\title{
DAVID YUDILEVICH LEVY, \\ CAMINANTE Y VISIONARIO (1930-2006)
}

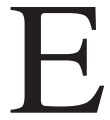
128 de mayo una noticia tan dolorosa como inesperada llegó desde Inglaterra: David Yudilevich había fallecido al mediodía. Iba camino hacia Tel Aviv, donde la semana siguiente debía dictar una conferencia sobre Alexander von Humboldt en el Instituto Cervantes. Su muerte ocurrió en el país que tanto amaba y que lo acogió cuando buscaba un lugar libre donde poder continuar sus investigaciones, como lo hicieron muchos científicos chilenos en la década del 70. Inglaterra fue su segunda patria y allí crecieron y viven actualmente sus hijos. Su comunidad científica lo valoró debidamente, incorporándolo como Professor (Head of Department) del afamado Queen Elizabeth College de la Universidad de Londres, con la responsabilidad de liderar el desarrollo de la disciplina, cargo que ejerció brillantemente por diez años. Luego fue nombrado Profesor del King's College, de la misma universidad. Sus trabajos sobre la permeabilidad de electrolitos y no electrolitos en capilares sanguíneos, y transporte de metabolitos a través de epitelios, especialmente a través de la placenta humana, fueron pioneros y son mundialmente reconocidos. En 1989 se acogió a retiro en la Universidad de Londres, que lo nombró Profesor Emérito, regresando a Chile como Profesor del Instituto de Ciencias Biomédicas de la Escuela de Medicina de la Universidad de Chile. Volvía así a la Universidad de Chile, donde inició su carrera científica, luego de titularse como Médico Cirujano. Su laboratorio, independiente del lugar donde estuviera, atrajo a jóvenes de talento, ávidos de recibir una buena formación científica. No solo eso recibieron ellos de David. Todos quienes se formaron junto a él saben de la alta exigencia que imponía al trabajo, pero también de la generosidad sin límites con que entregaba lo que sabía, y todos fueron tocados por su espíritu apasionado e inquisitivo. Su atractiva $\mathrm{y}$ brillante personalidad, sumada al contagioso entusiasmo que ponía en todo lo que le interesaba, cuyos límites trascendieron mucho más allá de la ciencia, infundían en sus discípulos una relación muy cercana con su maestro, con el cual nunca perdieron contacto. David formó a muchos científicos, entre ellos a Osvaldo Álvarez, Francisco Sepúlveda, Giovanni Mann, Felipe Barros y Luis Sobrevía. Con enorme generosidad, también ayudó de múltiples maneras y con gran decisión a muchos jóvenes a impulsar sus carreras científicas. Para lograr este objetivo no dudó, en varias oportunidades, en ignorar las convenciones y las reglas establecidas.

Lejos de retirarse a descansar luego de su alejamiento de la fisiología, David inició una nueva carrera, volcando todo su entusiasmo, energía y creatividad al estudio de dos grandes hombres, Charles Darwin y Alexander von Humboldt. Ambos representaban de alguna manera su espíritu. Eran viajeros curiosos, inteligentes y sabían ver lo que otros no percibían. Su mirada era amplia y trascendía las culturas. David quiso reclamarlos para América Latina y regalarle a nuestro continente su obra. Lo obsesionaba el desconocimiento, particularmente en Chile, del significado que tuvo este continente para sus respectivas investigaciones y quería repararlo. Con su mirada original de científico lúcido y riguroso abordó dichos estudios con pasión. Rápidamente ingresó al círculo selecto de los expertos mundiales en los respectivos temas, recibiendo invitaciones de todo el mundo a dictar conferencias o participar en encuentros sobre estos. Él mismo organizó entusiastamente varios eventos internacionales sobre estas materias en Chile y el extranjero. Con su libro Darwin en Chile puso al alcance de los chilenos el 
maravilloso libro del viaje que tanta relevancia tuvo para la teoría de la evolución. Antes del libro de David, la conexión de Darwin con Chile era ignorada por el gran público nacional. Algo similar logró con su otro libro, más reciente que el anterior, Humboldt y el camino del Inca, gracias al cual Humboldt, que tanto contribuyó al conocimiento científico de nuestro continente, ha ido paulatinamente dejando de ser un desconocido para los chilenos. David recorrió el mundo visitando metódicamente sitios que fueran importantes en los viajes de ambos personajes, revisando documentos relevantes para su trabajo en bibliotecas y otros lugares. Gran caminante, anduvo por el mundo cargando su pequeña mochila, muchas veces solo, y a pesar de su ceguera vio mucho más que nosotros. Suplía su pobre visión de las maneras más ingeniosas, utilizando grabadoras para guardar sus impresiones y las de sus interlocutores, y para escuchar libros o "leerlos", como el decía. Gracias a especiales lupas podía también ser un riguroso corrector de pruebas. Con su espíritu vibrante, su conversación interesante y entretenida, y total ausencia de arrogancia, fácilmente entraba en sintonía con gente de cualquier generación. Esto le permitía conseguir fácilmente a jóvenes talentosos que suplían sus limitaciones visuales, quienes además de ayudarlo eran incorporados por David a su tarea creativa. Su ceguera nunca interfirió seriamente en su trabajo, sino, por el contrario, lo ayudó a ver más.

David vivía creando e impulsando los más variados proyectos, en los cuales obsesivamente vertía su energía e imaginación. Muchos de ellos se encuentran en marcha y serán continuados por sus discípulos. Quienes tuvimos la fortuna de conocer de cerca a nuestro querido David y de vivir junto a él su pasión por la música, la buena literatura, el arte, los viajes y el paisaje chileno, sentiremos su presencia para siempre.

\section{JUAN BACIGALUPO}

Departamento de Biología, Facultad de Ciencias, Universidad de Chile

\section{ROSA DEVÉS}

Programa de Fisiología y Biofísica, Instituto de Ciencias Biomédicas, Universidad de Chile, Santiago, Chile 